\title{
Hyperleptinaemia, respiratory drive and hypercapnic response in obese patients
}

\author{
A. Campo*, G. Frühbeck", J.J. Zulueta*, J. Iriarte", L.M. Seijo*, A.B. Alcaide*, \\ J.B. Galdiz ${ }^{+}$and J. Salvador ${ }^{\#}$
}

ABSTRACT: Leptin is a powerful stimulant of ventilation in rodents. In humans, resistance to leptin has been consistently associated with obesity. Raised leptin levels have been reported in subjects with sleep apnoea or obesity-hypoventilation syndrome. The aim of the present study was to assess, by multivariate analysis, the possible association between respiratory centre impairment and levels of serum leptin.

In total, 364 obese subjects (body mass index $\geqslant 30 \mathrm{~kg} \cdot \mathrm{m}^{-2}$ ) underwent the following tests: sleep studies, respiratory function tests, baseline and hypercapnic response (mouth occlusion pressure $\left(P_{0.1}\right)$, minute ventilation), fasting leptin levels, body composition and anthropometric measures. Subjects with airways obstruction on spirometry were excluded.

Out of the $\mathbf{3 4 6}$ subjects undergoing testing, 245 were included in the current analysis. Lung volumes, age, log leptin levels, end-tidal carbon dioxide tension, percentage body fat and minimal nocturnal saturation were predictors for baseline $P_{0.1}$. The hypercapnic response test was performed by 186 subjects; log leptin levels were predictors for hypercapnic response in males, but not in females.

Hyperleptinaemia is associated with a reduction in respiratory drive and hypercapnic response, irrespective of the amount of body fat. These data suggest the extension of leptin resistance to the respiratory centre.

KEYWORDS: Control of breathing, hypoventilation, leptin, obesity, respiratory centre, respiratory function tests

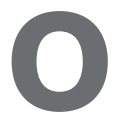
bese subjects have respiratory impairment [1] due to the increment of total body fat, which produces diminished compliance and increased resistance and work of breathing. In addition, a significant proportion suffer from obstructive sleep apnoea. A small subgroup, most of whom have sleep apnoea syndrome, have diurnal hypoventilation with hypoxaemia and hypercapnia [2]. Standard pulmonary function tests show a mild decrease in forced vital capacity (FVC) and forced expiratory volume in one second (FEV1), and a more evident reduction in expiratory reserve volume (ERV). Most of these subjects have an increased respiratory drive [3] and a diminished hypercapnic response. The latter is especially true in subjects with the obesity-hypoventilation syndrome [3, 4,]. These alterations are explained mainly by mechanical factors, as the extra fat load provokes a higher work of breathing and obstruction of the upper airways during sleep.
Some authors have, however, proposed the involvement of several adipose-derived factors $[5,6]$. In this context, leptin has emerged as a relevant adipokine playing a role as a stimulant of ventilation [5], with levels being raised in subjects with sleep apnoea syndrome or obesityelevation is attributed either to stimulation by hypoxia or to leptin insensitivity in obese subjects. In general, subjects with hypoventilation seem to exhibit higher levels of leptin for a given amount of body fat.

The aim of the present study was to assess the relationship between hyperleptinaemia and respiratory centre parameters after adjusting for respiratory impairment and the severity of obesity (sleep apnoea, nocturnal desaturation, restrictive pattern, percentage of body fat and fat distribution, age and sex), taking into account menopausal status in females. Serum leptin levels hypoventilation syndrome [6]. The reason for this

This article has supplementary material accessible from www.erj.ersjournals.com.

AFFILIATIONS

Depts of *Pulmonary Medicine,

\#Endocrinology, and

"Neurophysiology, Clinica

Universitaria de Navarra, University of

Navarra, Pamplona, and

${ }^{+}$Dept of Pulmonary Medicine,

Hospital de Cruces, Vizcaya, Spain.

CORRESPONDENCE

A. Campo

Pulmonary Medicine

Clinica Universitaria de Navarra

Avda. Pío XII

36

31008 Pamplona

Spain

Fax: 34948296500

E-mail: acampoe@unav.es

Received:

August 312006

Accepted after revision:

April 102007

STATEMENT OF INTEREST

None declared.

European Respiratory Journal

Print ISSN 0903-1936

Online ISSN 1399-3003 
correlate mainly with body fat percentage and logarithmic transformation improves linear correlation. Thus, log serum leptin was chosen as an independent variable.

\section{METHODS \\ Subjects}

Obese adult subjects ( $\geqslant 17$ yrs old and body mass index (BMI) $\geqslant 30 \mathrm{~kg} \cdot \mathrm{m}^{-2}$ ) referred for obesity treatment were included in the current analysis. Those with a diagnosis of restrictive pulmonary disease, neuromuscular disease or a previous pulmonary resection were excluded. Subjects with an obstructive spirometry pattern defined as an FEV1/FVC $<70 \%$ were also excluded. The protocol of the study was approved by the local Ethics Committee.

\section{Body composition}

Body fat percentage was assessed by air displacement plethysmography (Bod-Pod $₫$; Life Measurements, Concord, CA, USA), which is a previously validated bicompartmental method [7]. Waist and hip circumference were measured in all patients using a standard method [8]. Waist circumference was measured at the midpoint between the lateral lower ribs and the iliac crest, and hip circumference was measured at the level of the greatest extension of the hips.

\section{Serum leptin levels}

Fasting leptin levels were measured by a double antibody radioimmunoassay technique (Linco Research Inc., St Charles, $\mathrm{MO}, \mathrm{USA})$. Intra- and inter-assay coefficients of variation were 5.0 and $4.5 \%$, respectively.

\section{Polysomnographic study}

Those patients not previously tested underwent a polysomnographic study. Nocturnal sleep was recorded with Harmonie 5.2 (Stellate, Montreal, QC, Canada) using Lamont 32-Sleep amplifiers (Lamont Medical, Madison, WI, USA). The recordings included seven electroencephalogram channels referenced to both balanced mastoids, right and left electroculogram, oxygen saturation, airflow thoraco-abdominal bands, body position sensor and electrocardiogram. Apnoea was defined as cessation of nasal or oral airflow for $\geqslant 10 \mathrm{~s}$. Hypopnoea was defined as a $50 \%$ decrease in the airflow channel for $10 \mathrm{~s}$. The apnoea/hypopnoea index (AHI) was calculated as the mean number of apnoeic and hypopnoeic events per hour of sleep. The hypnogram was visually analysed off-line following standard criteria, while the programme automatically calculated the $\mathrm{AHI}$ and the frequency and severity of oxygen desaturations.

\section{Lung function tests}

Spirometry was performed with a calibrated, dry-rolling seal spirometer (SensorMedics 2130 System; SensorMedics Co., Yorba Linda, CA, USA) according to current guidelines. Static lung volumes were measured by body plethysmography (SensorMedics V6200 Autobox; SensorMedics Co.). The predicted values used for spirometric and thoracic gas volumes were those of the 1993 European update [9].

Patients underwent ventilatory drive assessment, including minute ventilation $\left(V^{\prime} \mathrm{E}\right)$, tidal volume $(V \mathrm{~T})$, inspiratory time $(t \mathrm{I})$, mouth occlusion pressure at $0.1 \mathrm{~s}$ of inspiration $\left(P_{0.1}\right)$ and end-tidal carbon dioxide tension $\left(P \mathrm{ET}, \mathrm{CO}_{2}\right) . P_{0.1}$ was measured using the method described by WHITELAW et al. [10]. The occlusion pressure valve was automatically occluded at random every 2-6 respiratory cycles, using software provided by SensorMedics. The hypercapnic response was assessed by the method described by READ [11] and the slope of $P_{0.1} /$ $P$ ET, $\mathrm{CO}_{2}$ and $V^{\prime} \mathrm{E} / P \mathrm{ET}, \mathrm{CO}_{2}$ was calculated by the minimal square regression method.

\section{Statistical analysis}

Variables are shown as mean $\pm \mathrm{SD}$. The effect of sex, menopausal status and obstructive sleep apnoea syndrome (OSAS) on the descriptive variables was initially analysed by Mann-Whitney U-test and the Chi-squared test. Bivariate correlations were studied using Spearman's rho correlation.

P0.1 analysis

Multivariate analysis was performed as a stepwise linear regression model with baseline $P_{0.1}$ as the dependent variable and age, sex, height, waist circumference, $\%$ body fat, total lung capacity (TLC) \% predicted, baseline $P \mathrm{ET}, \mathrm{CO}_{2}$, log serum leptin level, AHI and minimal and mean nocturnal oxygen saturation as independent variables. Male and female subjects were analysed both together and as separate groups. Menopausal status was included as an independent variable in the analysis of the females. The criteria for inclusion of variables into the stepwise linear regression were $p$ in 0.05 , $\mathrm{p}$ out 0.10 and minimal tolerance threshold $\left(1-\mathrm{r}^{2}\right)$ of 0.01 . A listwise exclusion for multivariate analysis was performed.

\section{Hypercapnic response}

The analysis of the hypercapnic response was performed with the same independent variables and slope of response $\left(P_{0.1} /\right.$ $P$ ET, $\left.\mathrm{CO}_{2}\right)$ as the dependent variable. A similar regression analysis was performed using $V^{\prime} \mathrm{E} / \mathrm{PET}, \mathrm{CO}_{2}$ as the dependent variable.

\section{RESULTS}

\section{Descriptive data}

In total, 364 subjects were included in the present study. Descriptive variables and differences between sex and between pre- and post-menopausal females are shown in table 1. The number of subjects undergoing the different tests is shown in table 2. Following exclusion of missing values from the multivariate analysis, 245 subjects were included in analysis of baseline respiratory centre assessment and 186 in the hypercapnic response assessment.

Sleep studies were performed in 194 females and 104 males. The AHI was between 5 and $30 \cdot \mathrm{h}^{-1}$ in 29.7 and $23.3 \%$ of females and males, respectively, and $>30 \cdot \mathrm{h}^{-1}$ in 15.1 and $44.7 \%$ of females and males, respectively $(\mathrm{p}<0.001)$.

Respiratory drive measurements were not different between subjects with or without OSAS (AHI $>$ or $<15 \cdot \mathrm{h}^{-1}$, respectively) after stratifying by sex, as shown in table 3 . Subjects with OSAS had a greater BMI, a larger waist circumference and a higher respiratory impairment.

The relationship between the percentage of body fat and leptin improved with logarithmic transformation; the linear correlation between leptin and percentage of body fat was stronger using $\log$ leptin $(R=0.629)$ rather than leptin $(R=0.565)$. The 
TABLE 1 Subject characteristics and comparison by sex and menopausal status

\begin{tabular}{|c|c|c|c|c|c|c|c|}
\hline & Total & Females & Males & p-value & Non-menopausal & Menopausal & $\mathrm{p}$-value \\
\hline Age yrs & $43.1 \pm 12.9$ & $43.7 \pm 13.1$ & $42.1 \pm 12.4$ & 0.256 & $35.53 \pm 9.71$ & $57.18 \pm 6.25$ & $<0.001$ \\
\hline Smoking & & & & 0.044 & & & 0.043 \\
\hline Current & $94(26)$ & $59(25.8)$ & $35(26.5)$ & & $43(33.1)$ & $12(16.7)$ & \\
\hline $\mathrm{BMI} \mathbf{k g} \cdot \mathrm{m}^{-2}$ & $43.0 \pm 6.86$ & $43.0 \pm 7.0$ & $42.91 \pm 6.6$ & 0.890 & $43.33 \pm 6.83$ & $42.43 \pm 7.52$ & 0.276 \\
\hline Waist-hip ratio & $0.94 \pm 0.09$ & $0.904 \pm 0.08$ & $1.002 \pm 0.08$ & $<0.001$ & $0.88 \pm 0.07$ & $0.94 \pm 0.07$ & $<0.001$ \\
\hline Waist $\mathbf{c m}$ & $122 \pm 14$ & $117 \pm 13$ & $129 \pm 13$ & $<0.001$ & $116.8 \pm 13$ & $119.72 \pm 12$ & 0.093 \\
\hline Body fat $\%$ & $48.9 \pm 7.2$ & $52.2 \pm 4.9$ & $42.9 \pm 6.8$ & $<0.001$ & $52.18 \pm 4.93$ & $52.64 \pm 4.29$ & 0.638 \\
\hline Leptin $\mu \mathrm{g} \cdot \mathrm{L}^{-1}$ & $54.5 \pm 30.2$ & $65.4 \pm 29.3$ & $36.0 \pm 21.4$ & $<0.001$ & $64.91 \pm 30.13$ & $64.64 \pm 28.96$ & 0.993 \\
\hline Log leptin $\mu \mathrm{g} \cdot \mathrm{L}^{-1}$ & $1.666 \pm 0.259$ & $1.769 \pm 0.212$ & $1.491 \pm 0.238$ & $<0.001$ & $1.76 \pm 0.22$ & $1.76 \pm 0.21$ & 0.993 \\
\hline Baseline $\mathrm{PET}, \mathrm{CO}_{2} \mathrm{mmHg}$ & $33.32 \pm 5.75$ & $32.97 \pm 5.743$ & $33.93 \pm 5.72$ & 0.126 & $32.51 \pm 5.34$ & $34.27 \pm 5.77$ & 0.025 \\
\hline$P_{0.1} /\left(V_{T} / t t\right) \mathrm{cmH}_{2} \mathrm{O} \cdot \mathrm{L}^{-1} \cdot \mathrm{s}^{-1}$ & $7.735 \pm 3.020$ & $7.850 \pm 2.885$ & $7.536 \pm 3.242$ & 0.086 & $8.00 \pm 2.68$ & $7.05 \pm 2.53$ & 0.007 \\
\hline $\mathrm{P}_{0.1} / \mathrm{PET}_{\mathrm{CO}} \mathrm{CO}_{2} \mathrm{cmH}_{2} \mathrm{O} / \mathrm{mmHg}$ & $1.01 \pm 0.90$ & $0.87 \pm 0.84$ & $1.27 \pm 0.94$ & $<0.001$ & $0.90 \pm 0.88$ & $0.82 \pm 0.75$ & 0.776 \\
\hline$V^{\prime} \mathrm{E} / \mathrm{PET}_{\mathrm{ET}} \mathrm{CO}_{2} \mathrm{~L} \cdot \mathrm{min}^{-1} / \mathrm{mmHg}$ & $2.61 \pm 1.87$ & $2.07 \pm 1.27$ & $3.60 \pm 2.34$ & $<0.001$ & $2.15 \pm 1.28$ & $1.92 \pm 1.29$ & 0.251 \\
\hline$A H I h^{-1}$ & $22.05 \pm 25.35$ & $15.53 \pm 18.21$ & $34.21 \pm 31.64$ & $<0.001$ & $13.79 \pm 18.54$ & $20.05 \pm 18.76$ & 0.002 \\
\hline Minimal $S_{p}, \mathrm{O}_{2} \%$ & $80.55 \pm 11.17$ & $82.13 \pm 10.64$ & $77.63 \pm 11.56$ & 0.001 & $84.4 \pm 10.31$ & $78.63 \pm 10.78$ & $<0.001$ \\
\hline Mean $\mathrm{Sp}, \mathrm{O}_{2} \%$ & $94.50 \pm 2.83$ & $94.83 \pm 2.61$ & $93.92 \pm 3.12$ & 0.016 & $95.46 \pm 2.45$ & $93.69 \pm 2.81$ & $<0.001$ \\
\hline
\end{tabular}

Variables are shown as mean \pm SD and categorical variables as absolute count $n(\%)$. BMI: body mass index; TLC: total lung capacity; \% pred: \% predicted; P0.1: mouth occlusion pressure; $\mathrm{PET}, \mathrm{CO}_{2}$ : end-tidal carbon dioxide tension; $\mathrm{VT}$ : tidal volume; tI: time taken for inspiration; $V^{\prime} \mathrm{E}:$ minute ventilation; AHI: apnoea/hypopnoea index; $\mathrm{Sp}, \mathrm{O}_{2}$ arterial oxygen saturation. $1 \mathrm{mmHg}=0.133 \mathrm{kPa}$

correlation of body fat and log leptin was 0.342 and 0.513 for females and males, respectively.

\section{Bivariate correlations}

Bivariate correlations are shown in tables 4, 5 and 6 for P0.1, hypercapnic response by $P 0.1$ and hypercapnic response by

TABLE 2 Number of subjects who underwent each test

\begin{tabular}{llcl} 
& Females & Males & Total \\
\hline $\begin{array}{l}\text { Spirometry } \\
\text { Baseline P0.1/ respiratory }\end{array}$ & $231(100)$ & $133(100)$ & $364(100)$ \\
$\quad$ pattern & $229(99.1)$ & $132(99.25)$ & $361(99.2)$ \\
Hypercapnic response & $159(68.8)$ & $86(64.7)$ & $245(67.3)$ \\
Polysomnographic study & $194(84)$ & $104(78.2)$ & $298(81.87)$ \\
AHI & $192(83.1)$ & $103(77.4)$ & $295(81.0)$ \\
Minimal Sp, $\mathbf{O}_{2} \%$ & $195(84.4)$ & $106(79.7)$ & $301(82.69)$ \\
Mean Sp, $\mathbf{O}_{2} \%$ & $174(75.3)$ & $96(72.2)$ & $270(74.2)$ \\
Body composition & $220(95.2)$ & $125(94.0)$ & $345(94.8)$ \\
Leptin & $224(97)$ & $131(98.5)$ & $355(97.5)$ \\
Waist & $223(96.5)$ & $131(98.5)$ & $354(97.3)$ \\
\hline
\end{tabular}

Data are presented as $\mathrm{n}(\%)$. P0.1: mouth occlusion pressure; AHI: apnoea/ hypopnoea index; $\mathrm{Sp}, \mathrm{O}_{2}$ : arterial oxygen saturation. minute ventilation, respectively. Each table provides data for the whole sample, males and females.

\section{Multivariate analysis models}

The multivariate analysis included the following variables: age, obesity parameters (percentage of body fat and fat distribution), log leptin levels, pulmonary function (TLC \% pred) and sleep study parameters (AHI, minimal and mean nocturnal saturation). Analysis of the whole group included sex as a variable, and the analysis of females included menopausal status. After bivariate analysis, waist-hip ratio and waist circumference were used as a measurement of fat distribution in males and females, respectively.

The results of the multiple linear regression analyses are summarised in table 7. Figure 1 shows significant adjusted partial correlation between log leptin levels and $P_{0.1}$ in males and pre-menopausal females and log leptin levels and hypercapnic response in males, after the multivariate analysis. Other partial correlations between respiratory centre parameters and significant variables after multivariate analysis are shown in the supplementary material.

\section{Baseline $P 0.1$}

The variables associated with $P 0.1$ in the whole sample were age, percentage of body fat, log leptin levels, TLC \% pred, baseline $P \mathrm{ET}, \mathrm{CO}_{2}$ and minimal nocturnal saturation. In males, the associated variables were percentage of body fat, log leptin 
TABLE 3 Differences between subjects with and without obstructive sleep apnoea syndrome (OSAS) stratified by sex

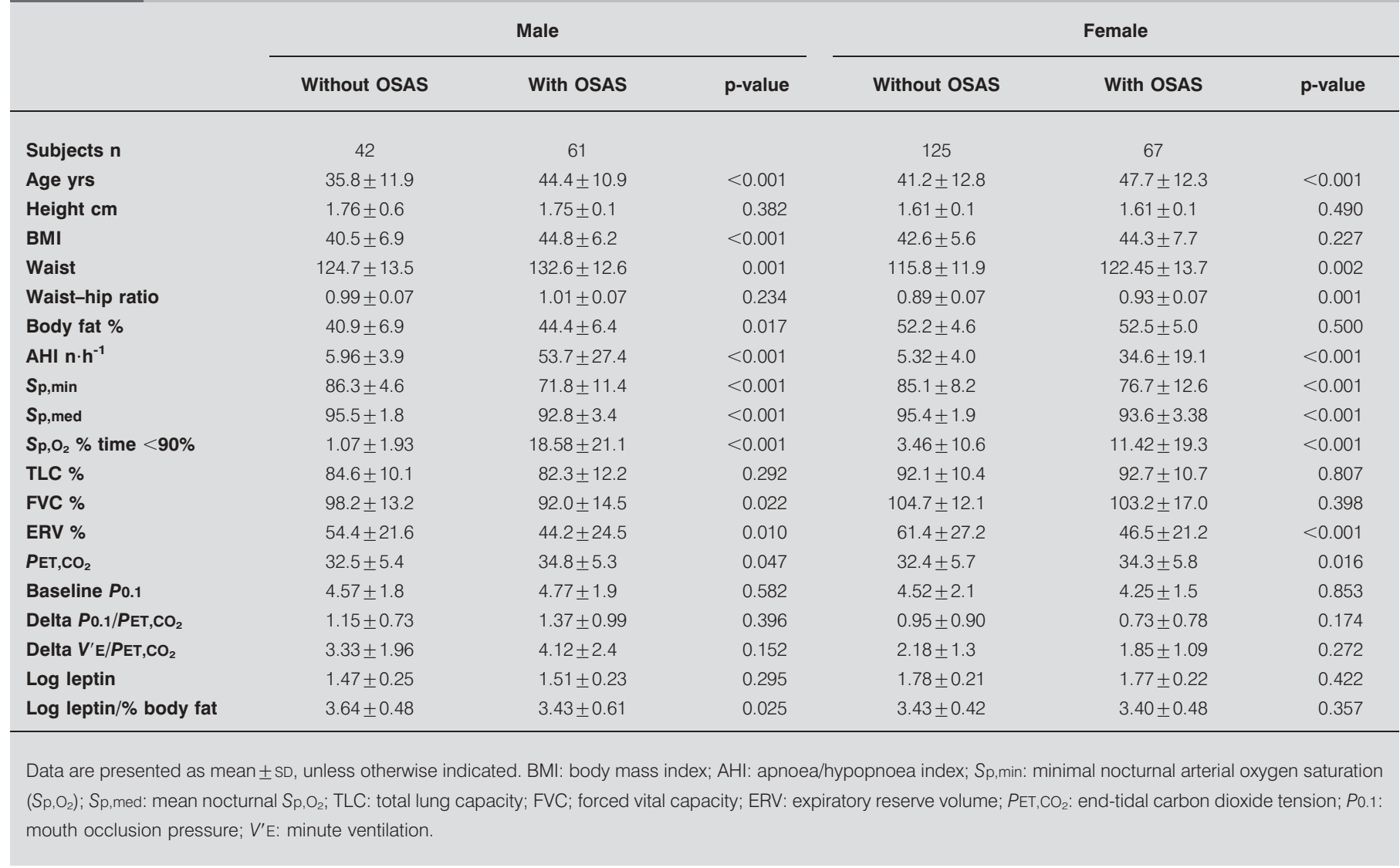

TABLE 4 Spearman's rho bivariate correlations for baseline mouth occlusion pressure $(P 0.1)$

\begin{tabular}{|c|c|c|c|c|c|c|c|c|}
\hline \multirow[t]{2}{*}{ Variable } & \multicolumn{2}{|c|}{ Whole sample } & \multicolumn{2}{|c|}{ Males } & \multicolumn{4}{|c|}{ Females } \\
\hline & Rho & $p$-value & Rho & $\mathrm{p}$-value & \multicolumn{2}{|c|}{ Pre-menopausal } & \multicolumn{2}{|c|}{ Post-menopausal } \\
\hline Height & 0.092 & 0.080 & 0.071 & 0.421 & -0.060 & 0.498 & -0.012 & 0.923 \\
\hline Age & -0.154 & 0.003 & -0.080 & 0.360 & -0.092 & 0.296 & -0.045 & 0.708 \\
\hline Leptin & -0.048 & 0.371 & 0.010 & 0.908 & -0.024 & 0.787 & -0.035 & 0.775 \\
\hline Log leptin & -0.048 & 0.371 & 0.010 & 0.908 & -0.024 & 0.787 & -0.035 & 0.775 \\
\hline Leptin ${ }^{\#}$ & -0.151 & 0.005 & -0.143 & 0.117 & -0.126 & 0.164 & -0.081 & 0.530 \\
\hline Log leptin\# & -0.146 & 0.008 & -0.153 & 0.093 & -0.105 & 0.249 & -0.063 & 0.626 \\
\hline Log leptin/\% body fat & -0.176 & 0.001 & -0.259 & 0.004 & -0.161 & 0.075 & 0.014 & 0.912 \\
\hline Waist & 0.147 & 0.006 & 0.105 & 0.233 & 0.125 & 0.161 & 0.058 & 0.636 \\
\hline Minimal $\mathrm{Sp}_{\mathrm{p}, \mathrm{O}_{2}}$ & -0.076 & 0.192 & -0.017 & 0.863 & -0.132 & 0.160 & -0.097 & 0.480 \\
\hline Mean $\mathrm{Sp}, \mathrm{O}_{2}$ & -0.065 & 0.289 & -0.084 & 0.414 & -0.170 & 0.084 & -0.063 & 0.659 \\
\hline Sex & 0.092 & 0.080 & & & & & & \\
\hline
\end{tabular}

TLC: total lung capacity; \% pred: \% predicted; $\mathrm{PET}, \mathrm{CO}_{2}$ : end-tidal carbon dioxide tension; $\mathrm{AHI}$ : apnoea/hypopnoea index; $\mathrm{Sp}, \mathrm{O}_{2}$ : arterial oxygen saturation. ${ }^{\#}$ : bivariate correlations adjusted by $\%$ body fat. 
TABLE 5 Bivariate correlations with hypercapnic response (mouth occlusion pressure/end-tidal carbon dioxide tension $\left(P E T, \mathrm{CO}_{2}\right)$ )

\begin{tabular}{|c|c|c|c|c|c|c|c|c|}
\hline \multirow[t]{2}{*}{ Variable } & \multicolumn{2}{|c|}{ Whole sample } & \multicolumn{2}{|c|}{ Males } & \multicolumn{4}{|c|}{ Females } \\
\hline & Rho & p-value & Rho & p-value & \multicolumn{2}{|c|}{ Pre-menopausal } & \multicolumn{2}{|c|}{ Post-menopausal } \\
\hline Height & 0.252 & $<0.001$ & 0.077 & 0.480 & 0.165 & 0.110 & 0.173 & 0.234 \\
\hline Leptin & -0.151 & 0.019 & 0.010 & 0.931 & -0.002 & 0.988 & 0.036 & 0.809 \\
\hline Log leptin & -0.151 & 0.019 & -0.010 & 0.931 & -0.002 & 0.988 & 0.036 & 0.809 \\
\hline Leptin ${ }^{\#}$ & -0.072 & 0.281 & -0.148 & 0.200 & -0.051 & 0.633 & 0.155 & 0.315 \\
\hline Log leptin $\#$ & -0.094 & 0.156 & -0.256 & 0.025 & -0.030 & 0.780 & 0.163 & 0.291 \\
\hline Log leptin/\% body fat & 0.104 & 0.121 & -0.123 & 0.288 & 0.072 & 0.503 & 0.359 & 0.017 \\
\hline Waist & -0.018 & 0.779 & -0.029 & 0.796 & -0.148 & 0.155 & -0.090 & 0.541 \\
\hline Sp,min & 0.112 & 0.108 & -0.019 & 0.879 & 0.226 & 0.038 & 0.071 & 0.666 \\
\hline Sp,med & 0.080 & 0.258 & -0.141 & 0.260 & 0.222 & 0.042 & 0.167 & 0.309 \\
\hline Sex & 0.256 & $<0.001$ & & & & & & \\
\hline
\end{tabular}

TLC: total lung capacity; \% pred: \% predicted; AHI: apnoea/hypopnoea index; $\mathrm{Sp}$,min: minimal nocturnal arterial oxygen saturation $\left(\mathrm{Sp}, \mathrm{O}_{2}\right) ; \mathrm{Sp}, \mathrm{med}$ : mean nocturnal $\mathrm{Sp}, \mathrm{O}_{2}$.

\#: bivariate correlations adjusted by $\%$ body fat.

levels, TLC \% pred, baseline PET, $\mathrm{CO}_{2}$, minimal nocturnal saturation and waist-hip ratio. In this group, log leptin levels accounted for a change in $r^{2}$ of 0.029 , with a p-value for the change in $\mathrm{F}$ of 0.050 . The analysis in females showed a significant association with log leptin levels in pre-menopausal but not in post-menopausal females, which accounted for a change in $\mathrm{r}^{2}$ of $0.05(\mathrm{p}=0.017)$. The other explanatory variables in this group were age, percentage of body fat and $\mathrm{PET}, \mathrm{CO}_{2}$.

TABLE 6 Bivariate correlations for hypercapnic response (minute ventilation/end-tidal carbon dioxide tension $\left(P E T, \mathrm{CO}_{2}\right)$ )

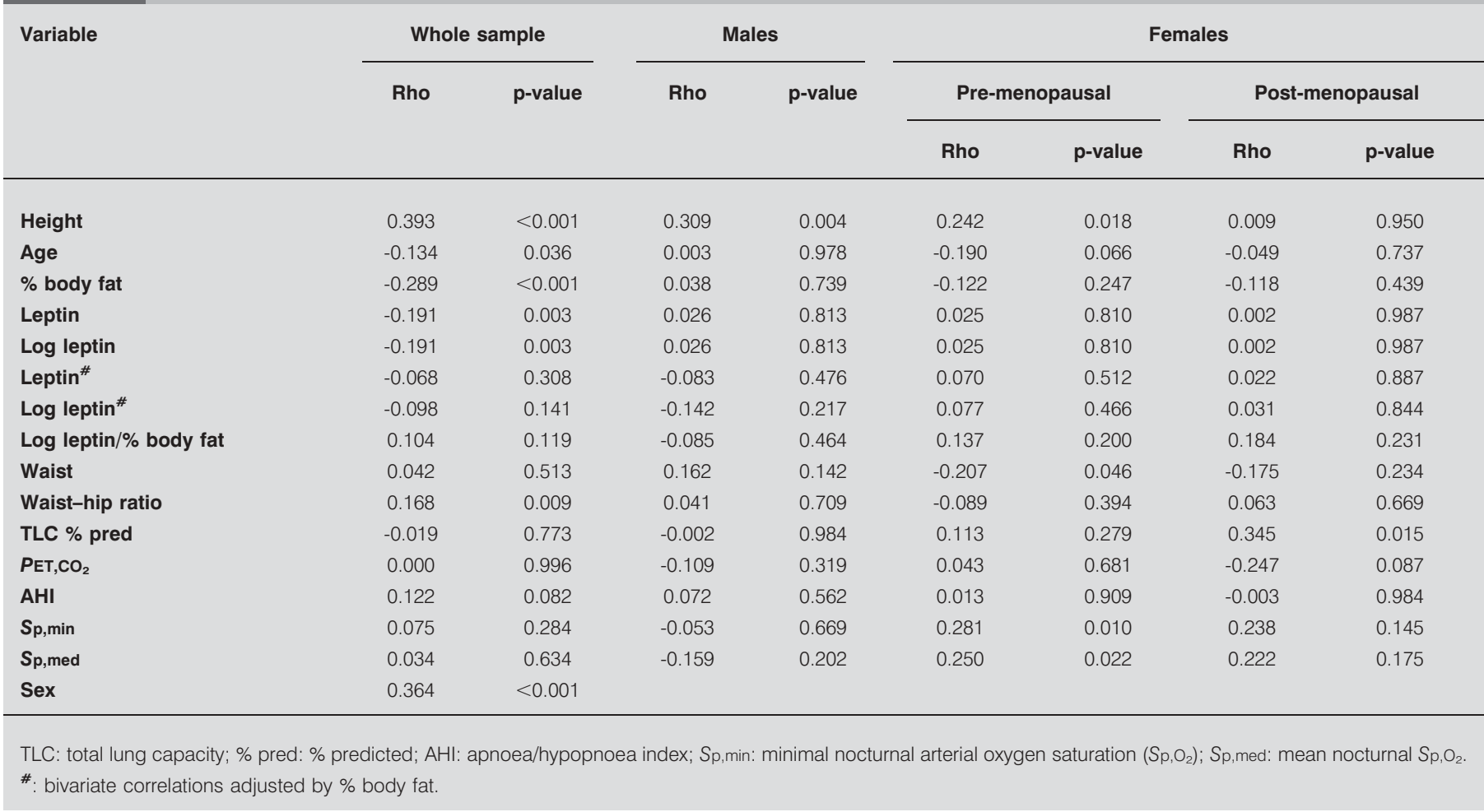




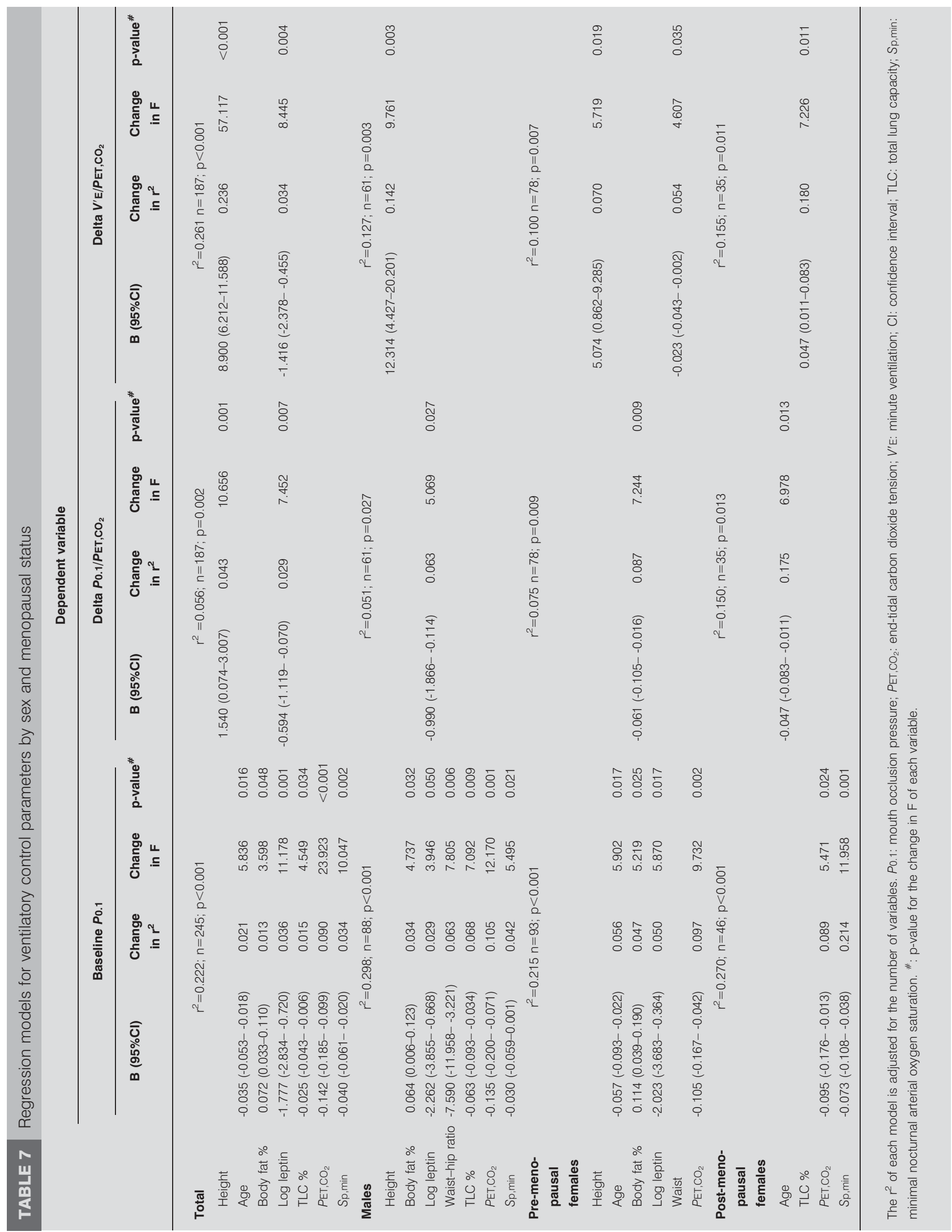



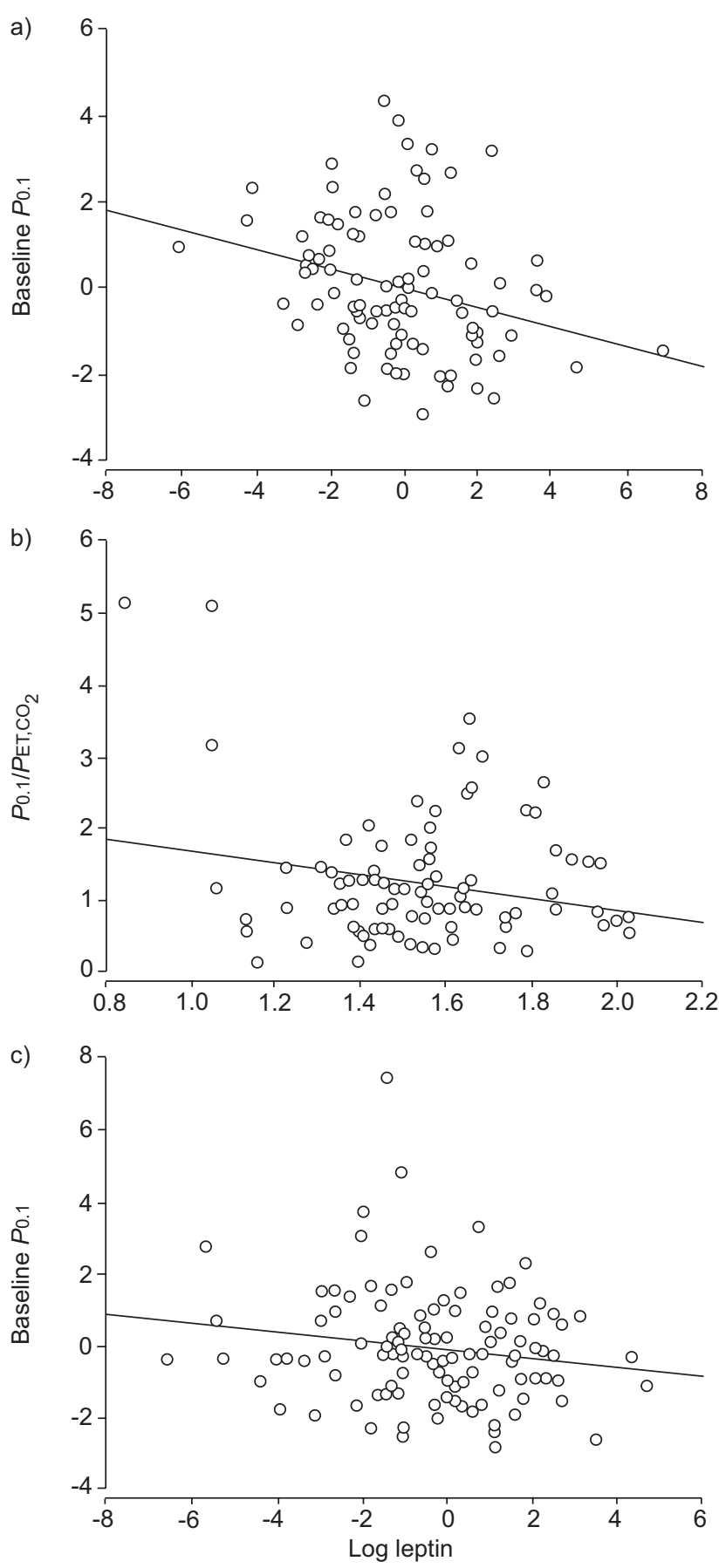

FIGURE 1. Partial correlations between log leptin levels and respiratory control parameters that were significant in the multivariate analysis. a) Partial correlation between log leptin levels and baseline mouth occlusion pressure $\left(P_{0.1}\right)$ in males after adjusting multivariate analysis. $r^{2}=0.0795$. b) Correlation between log leptin levels and delta $P_{0.1} /$ end-tidal carbon dioxide tension $\left(P \mathrm{ET}, \mathrm{CO}_{2}\right)$ in males. $r^{2}=0.0406$ c) Partial correlation between log leptin levels and baseline $P_{0.1}$ in pre-menopausal females after adjusting multivariate analysis. $r^{2}=0.0253$

\section{Hypercapnic response}

The multivariate analysis for hypercapnic response showed that the explained variability of the slope of $P_{0.1} / \mathrm{PET}_{\mathrm{E}} \mathrm{CO}_{2}$ was $5.6 \%(p=0.002)$, with height and leptin levels as the only explanatory variables. The separate analyses showed that log leptin level was the only explanatory variable in males $\left(\mathrm{r}^{2}=0.051 ; \mathrm{p}=0.027\right)$, but was not an explanatory variable in females.

The regression analysis for $V^{\prime} \mathrm{E} / \mathrm{PET}, \mathrm{CO}_{2}$ showed an explained variability of $26.1 \%(p<0.001)$, with height and log leptin levels as independent variables. The separate analyses showed that height was the only explanatory variable in males. In premenopausal females, height and waist were explanatory variables; in post-menopausal females, TLC \% pred was the only independent variable.

\section{DISCUSSION}

The present study demonstrates that in obese patients, higher concentrations of serum leptin are associated with a reduced respiratory drive and a reduced hypercapnic response. As leptin is a stimulant of ventilation, these results suggest an extension of leptin resistance to the respiratory centre. Clinical studies of obesity-hypoventilation syndrome have suggested an association between respiratory drive and leptin but this has not previously been demonstrated.

Leptin, the product of the $O b$ gene, is a protein secreted by adipocytes that regulates body weight [12-14] by increasing satiety and reducing food intake. Serum leptin levels correlate with body fat percentage [15]. It has been shown that, in mice, leptin deficiency induced by an $\mathrm{Ob}$ gene mutation is associated with morbid obesity, hyperphagia, insulin resistance and hypoventilation. Seminal studies in animals describe the characteristic hypoventilation of mice associated with $\mathrm{Ob}$ mutation and the subsequent improvement with exogenous leptin administration, even before the consequent reduction in body weight [5]. Prolonged treatment (6 weeks) with leptin in leptin-deficient mice modifies the animal's ventilatory pattern, increases lung compliance and restores the abnormal adaptation of the diaphragm [16]. While most obese subjects have markedly increased levels of plasma leptin, only a few cases of human genetic abnormalities of leptin have been reported. Obesity has been postulated to be a state of leptin resistance. Two distinct mechanisms of resistance have been proposed in human obesity: an impaired transport of leptin across the blood-brain barrier $[17,18]$ and altered signalling pathways or receptors. Leptin resistance can also be induced by feeding animals a high-fat diet [19].

The possible interaction between leptin and ventilatory parameters in humans is not as clear as that seen in animal models. Most of the studies in this regard have investigated the relationship between leptin levels, sleep apnoea syndrome and obesity-hypoventilation syndrome. However, there are no studies assessing the relationship between the respiratory centre and leptin in humans.

Compared with BMI-matched controls, higher plasma levels of leptin are described in hypercapnic obese subjects and those with OSAS [20, 21]. Furthermore, treatment of the latter with continuous positive airway pressure reduces plasma leptin levels [22-26]. Possible explanations for the reduction in leptin levels after treatment include a change in fat distribution [25], an improvement in sympathetic function [27] or an improvement in leptin sensitivity. However, the existence of an independent association between leptin and OSAS is controversial. Some studies have failed in their attempts to 
demonstrate the existence of this relationship, independent of adiposity [26, 28].

Another hypothesis is that hypoxaemia causes leptin secretion; this has been shown in experimental studies [29]. In this hypothesis, leptin resistance and hyperleptinaemia might not cause hypoventilation but might be caused by it. TATSUMI et al. [30] studied 96 male nonobese patients with OSAS and 52 male patients without OSAS matched for BMI, and found that the average arterial oxygen saturation $\left(\mathrm{Sa}_{\mathrm{a}} \mathrm{O}_{2}\right)$ and lowest $\mathrm{Sa}_{\mathrm{a}} \mathrm{O}_{2}$ were explanatory variables for serum leptin values, but AHI, BMI, visceral fat or subcutaneous fat were not. These results suggest that the elevation of leptin levels was a consequence of hypoxia and not of fat accumulation.

The present study analysed a larger size sample (245 subjects) than in previous studies, and in addition to body composition, also took into account fat distribution, nocturnal saturation, AHI, pulmonary function and sex. Leptin levels were an independent factor of respiratory drive, independent of apnoea events, nocturnal saturation, restrictive impairment or fat distribution. There are no previous studies in humans that analyse correlate respiratory drive measurements with leptin, although the relationship between hypercapnia and circulating leptin levels has been reported. However, as the present study is a cross-sectional study, the results cannot imply causality. These results are significant in the whole sample and in males, but the association in females could not be demonstrated. The association is weak, and log leptin levels account only for a 2.9 and $6.3 \%$ of the variance of baseline $P_{0.1}$ and delta $P_{0.1} / \mathrm{PET}_{\mathrm{E}} \mathrm{CO}_{2}$ in males, so the size of the sample and the differences in the behaviour of leptin in females might explain the lack of significance in females.

PHIPPs et al. [6] found higher serum leptin levels in subjects with obesity-hypoventilation syndrome than in subjects with the same amount of body fat but without hypoventilation; the severity of OSAS had no effect. SHIMURA et al. [31] studied 185 male patients with OSAS (106 eucapnic and 79 hypercapnic) in which visceral and subcutaneous fat distribution was assessed by computed tomography. They found that leptin, and not fat distribution, was the only predictor of hypercapnia. No association was found between circulating leptin levels and AHI, nocturnal mean and nadir oxygen saturation, percentage of FVC, FEV1/FVC or fat content. They suggest that hypoventilation in OSAS is partly due to depressed sensitivity to leptin in the CNS.

One limitation of the present study is that arterial blood gas analysis was not performed, so it is impossible to be certain as to how many of the present study's subjects had established hypoventilation-obesity syndrome.

In the present study, respiratory drive measured as baseline $P_{0.1}$ was increased with respect to other studies [32, 33], although a control group assessment was not performed. There was a significant and independent correlation between the presence of a restrictive impairment and the increment in respiratory drive, as has been seen in obese subjects. This suggests a stimulation of the respiratory centre by the increased work of breathing. Respiratory drive also correlated positively with the severity of obesity defined as percentage body fat, and inversely with baseline $\mathrm{PET}, \mathrm{CO}_{2}$, age and minimal nocturnal saturation. The nadir $\mathrm{Sp}_{\mathrm{p}} \mathrm{O}_{2}$ was an independent variable for baseline $P_{0.1}$ in males and post-menopausal females. The respiratory centre parameters were not different between subjects with and without OSAS.

Bivariate analysis did not demonstrate significant correlations between $\mathrm{AHI}$ and ventilatory control parameters, although there were significant correlations with nocturnal saturation indices. However, the effect of respiratory disorders during sleep was also assessed by including AHI and minimal and mean nocturnal saturation in the multivariate analysis.

No association was found between the AHI or saturation parameters with hypercapnic response. Studies have found that the hypercapnic response is increased in obese females irrespective of the presence of sleep apnoea syndrome, whereas the hypoxic response is significantly increased in obese females with OSAS compared with obese females without OSAS [34].

The hypercapnic response in males, measured by the increase in minute ventilation, had a strong correlation with height, as height correlates with absolute TLC and baseline minute ventilation. In females this response correlated with height but also with the presence of a restrictive pattern and waist circumference, probably reflecting mechanical limitations for ventilation.

Differences in variables between sexes were analysed. Several obesity and respiratory variables, but not BMI, were significantly different between males and females. Females had a different fat distribution, higher circulating leptin levels and a greater percentage of body fat, but fewer alterations in lung volumes and fewer and milder respiratory disorders during sleep. Sexual dimorphism in leptin levels has been repeatedly reported [35]. This finding may be attributed to the different distribution of fat in both sexes, as visceral fat produces less leptin and is found in higher proportion in males. However, no effect of female sex or menopausal status was found on the respiratory centre measurements.

In conclusion, a lower respiratory drive in obese subjects is associated with higher serum leptin levels, adjusted by ventilatory parameters, age, severity of obesity, apnoeahypopnoea index and nocturnal saturation. In males higher leptin levels are also associated with a lower hypercapnic response. These results suggest an extension of leptin resistance to the respiratory centre in obese subjects.

\section{ACKNOWLEDGEMENTS}

The authors wish to thank T. Jimenez and E. de Miguel (Pulmonary Function Laboratory, Dept of Pulmonary Medicine, University of Navarra, Pamplona, Spain) for their invaluable technical assistance.

\section{REFERENCES}

1 Rochester DF, Enson Y. Current concepts in the pathogenesis of the obesity-hypoventilation syndrome. Mechanical and circulatory factors. Am J Med 1974; 57: 402-420.

2 Kessler R, Chaouat A, Schinkewitch P, et al. The obesityhypoventilation syndrome revisited. A prospective study of 34 consecutive cases. Chest 2001; 120: 369-376. 
3 Sampson MG, Grassino A. Neuromechanical properties in obese patients during carbon dioxide rebreathing. Am J Med 1983; 75: 81-90.

4 Zwillich CW, Sutton FD, Pierson DJ, Creagh EM, Weil JV. Decreased hypoxic ventilatory drive in the obesityhypoventilation syndrome. Am J Med 1975; 59: 343-348.

5 O'Donnell CP, Schaub CD, Haines AS, et al. Leptin prevents respiratory depression in obesity. Am J Respir Crit Care Med 1999; 159: 1477-1484.

6 Phipps PR, Sarritt E, Caterson I, Grunstein RR. Association of serum leptin with hypoventilation in human obesity. Thorax 2002; 57: 75-76.

7 Ginde SR, Geliebter A, Rubiano F, et al. Air displacement plethysmography: validation in overweight and obese subjects. Obes Res 2005; 13: 1232-1237.

8 Wahrenberg H, Hertel K, Leijonhufvud BM, Persson LG, Toft E, Arner P. Use of waist circumference to predict insulin resistance: retrospective study. BMJ 2005; 330: 1363-1364.

9 Quanjer PH, Tammeling GJ, Cotes JE, Pedersen OF, Peslin R, YErnault JC. Lung volumes, forced ventilatory flows. Report Working Party Standardization of Lung Function Tests, European Community for Steel and Coal. Official Statement of the European Respiratory Society. Eur Respir J 1993; 6: Suppl. 16, 5-40.

10 Whitelaw WA, Derenne J-P, Milic-Emili J. Occlusion pressure as a measure of respiratory center output in conscious man. Respir Physiol 1975; 23: 181-199.

11 Read DJ. A clinical method for assessing the ventilatory response to carbon dioxide. Australas Ann Med 1967; 16: 20-32.

12 Haalas JL, Gajiwala KS, Maffei M, et al. Weight-reducing effects of the plasma protein encoded by the obese gene. Science 1995; 269: 543-546.

13 Zhang Y, Proenca R, Maffei M, Barone M, Leopold L, Friedman JM. Positional cloning of the mouse obese gene and its human homologue. Nature 1994; 372: 425-432.

14 Pelleymounter MA, Cullen MJ, Baker MB, et al. Effects of the obese gene product on body weight regulation in ob/ ob mice. Science 1995; 269: 540-543.

15 Considine RV, Sinha MK, Heiman ML, et al. Serum immunoreactive-leptin concentrations in normal-weight and obese humans. N Engl J Med 1996; 334: 292-295.

16 Tankersley CG, O'Donnell C, Daood MJ, et al. Leptin attenuates respiratory complications associated with the obese phenotype. J Appl Physiol 1998; 85: 2261-2269.

17 Caro JF, Kolaczynski JW, Nyce MR, et al. Decreased cerebrospinal-fluid/serum leptin ratio in obesity: a possible mechanism for leptin resistance. Lancet 1996; 348: 159-161.

18 Banks WA, DiPalma CR, Farrell CL. Impaired transport of leptin across the blood-brain barrier in obesity. Peptides 1999; 20: 1341-1345.

19 Frederich RC, Hamann A, Anderson S, Löllmann B, Lowell BB, Flier JS. Leptin levels reflect body lipid content in mice: evidence for a diet-induced resistance to leptin action. Nat Med 1995; 1: 1311-1314.
20 Vgontzas AN, Papanicolaou DA, Bixler EO, et al. Sleep apnea and daytime sleepiness and fatigue: relation to visceral obesity, insulin resistance, and hypercytokinemia. J Clin Endocrinol Metab 2000; 85: 1151-1158.

21 Öztürk L, Ünal M, Tamer L, Çelikoglu F. The association of the severity of obstructive sleep apnea with plasma leptin levels. Arch Otolaryngol Head Neck Surg 2003; 129: 538-540.

22 Saarelainen S, Lahtela J, Kallonen E. Effect of nasal CPAP treatment on insulin sensitivity and plasma leptin. J Sleep Res 1997; 6: 146-147.

23 Harsch IA, Konturek PC, Koebnick C, et al. Leptin and ghrelin levels in patients with obstructive sleep apnoea: effect of CPAP treatment. Eur Respir J 2003; 22: 251-257.

24 Chin K, Shimizu K, Nakamura T, et al. Changes in intraabdominal visceral fat and serum leptin levels in patients with obstructive sleep apnea syndrome following nasal continuous positive airway pressure therapy. Circulation 1999; 100: 706-712.

25 Ip MS, Lam KS, Ho C, Tsang KW, Lam W. Serum leptin and vascular risk factors in obstructive sleep apnea. Chest 2000; 118: 580-586.

26 Sanner BM, Kollhosser P, Buechner N, Zidek W, Tepel M. Influence of treatment on leptin levels in patients with obstructive sleep apnoea. Eur Respir J 2004; 23: 601-604.

27 Shimizu K, Chin K, Nakamura T, et al. Plasma leptin levels and cardiac sympathetic function in patients with obstructive sleep apnoea-hypopnoea syndrome. Thorax 2002; 47: 429-434.

28 Barceló A, Barbé F, Llompart E, et al. Neuropeptide Y and leptin in patients with obstructive sleep apnea syndrome. Am J Respir Crit Care Med 2004; 171: 183-187.

29 Grosfeld A, André J, Hauguel-de Mouzon S, Berra E, Pouysségur J, Guerre-Millo. Hypoxia-inducible factor 1 transactivates the human leptin gene promoter. J Biol Chem 2002; 45: 42953-42957.

30 Tatsumi K, Kasahara Y, Kurosu K, Tanabe N, Takiguchi Y, Kuriyama T. Sleep oxygen desaturation and circulating leptin in obstructive sleep apnea-hypopnea syndrome. Chest 2005; 127: 716-721.

31 Shimura R, Tatsumi K, Nakamura A, et al. Fat accumulation, leptin, and hypercapnia in obstructive sleep apneahypopnea syndrome. Chest 2005; 127: 543-549.

32 Van Klaveren RJ, Demedts M. Determinants of hypercapnic and hypoxic response in normal man. Respir Physiol 1998; 113: 157-165.

33 Montes de Oca M, Celli BR. Mouth occlusion pressure, $\mathrm{CO}_{2}$ response and hypercapnia in severe chronic obstructive pulmonary disease. Eur Respir J 1998; 12: 666-671.

34 Buyse B, Markous N, Cauberghs M, Van Klaveren R, Muls E, Demedts M. Effect of obesity and/or sleep apnea on chemosensitivity: differences between men and women. Respir Physiol Neurobiol 2003; 1334: 13-22.

35 Saad MF, Damani S, Gingerich RL, et al. Sexual dimorphism in plasma leptin concentration. J Clin Endocrinol Metab 1997; 82: 579-584. 